\title{
Antiproliferative activity of pure lycopene compared to both extracted lycopene and juices from watermelon (Citrullus vulgaris) and papaya (Carica papaya) on human breast and liver cancer cell lines
}

\begin{abstract}
Lycopene is one of the major carotenoids in the diet and is believed to have a number of health benefits including anticancer properties. This investigation was conducted with the aim of screening the potential anticancer properties of pure lycopene and of both extracted lycopene and juices from watermelon and papaya. Two different types of human tumor cell lines, HepG2 (liver cancer cell line) and MDA-MB-231 (breast cancer cell line) were used for the evaluation of cytotoxicity effects. Chang liver cell line that is the transformed cell for the liver was used for comparison. The cells treated with pure lycopene, extracted lycopene and juices from both watermelon and papaya were maintained and incubated at $37^{\circ} \mathrm{C}$ in $5 \%$ $\mathrm{CO} 2$ for five days. The Microculture Tetrazolium salt (MTT) assay was carried out in this investigation, to determine the cell viability. Pure lycopene was found to cause $50 \%$ cell death (IC50) of HepG2 cells at a concentration of $22.8 \mu \mathrm{g} \mathrm{ml}-1$, while papaya juice at a concentration of $20 \mathrm{mg} \mathrm{ml}-1$. In the case of MDA-MB-231 cells, the IC50 of the watermelon was $11.3 \mathrm{mg} \mathrm{ml}-1$. The other samples including extracted lycopene samples did not show any effect in the cell viability. The findings of this study showed that pure lycopene and papaya juice may have anticancer properties upon liver cancer cell line (HepG2), while watermelon juice had anticancer properties against breast cancer cell line (MDA-MB-231). The juices seemed to be more effective than the extracted lycopene samples in inhibiting cancer cell growth.
\end{abstract}

Keyword: Pure lycopene; Extracted lycopene; Juices from watermelon; Juices from papaya; HepG2; MDA-MB-231; MTT assay; Cell vialibity 